- $\quad$ is involved in multiple community service activities

- has prior experience serving on an IACUC

- would abide by confidentiality agreements at both institutions

We feel that these qualities outweigh any perception of Rubin's affiliation to Starling College.
Raja Sriperumbudur ${ }^{凶}$ and Cheryl Cheney

Biogen, Cambridge, MA, USA.

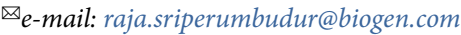

Published online: 24 June 2020

https://doi.org/10.1038/s41684-020-0577-2

References

1. PHS Policy IV.A. 3. b. (4) Public Health Service. Policy on Humane Care and Use of Laboratory Animals IV.A. 3. b. (4) (US Department of Health and Human Services, Washington, DC, 1986; amended 2002).
2. Animal Welfare Act (7 USC, Ch. $54, \$ 2143$ (b)(1)(B) (p.13 in Blue Book)

3. Animal Welfare Regulations 9 CFR, $\$ 2.31$ (b)(3)(ii) (p. 56 in Blue Book)

4. Institute of Laboratory Animal Research. Guide for the care and use of laboratory animals p24 (The National Academies Press, Washington, DC, 2011).

5. National Institutes of Health. NOT-OD-15-109 - Guidance on Qualifications of IACUC Nonscientific and Nonaffiliated Members. June 9, 2015

6. Silverman, J., Suckow, M. A., Murthy, S. (eds.). The IACUC Handbook Section 5:35. (CRC Press, Washington, DC, 2014). 7. Animal Welfare Act (7 USC, Ch. 54, 22157 (p.25 in Blue Book)

\title{
Acting professionally and impartially
}

$\mathrm{N}$ onaffiliated members are an integral part of the IACUC system. Rubin, with her years of experience as an IACUC member (nonscientific) at Great Eastern University, will be an excellent resource for the IACUC at Starling College.

All IACUC members are expected to act professionally and impartially in considering IACUC matters. Rubin would be well aware of this, and she should not have had second thoughts on having concurrent roles in the two IACUCs. Institutions should have established procedures to manage conflict of interests and confidentiality. IACUC members would be required to sign a confidentiality and non-disclosure agreement ${ }^{1}$. Rubin's previous employment with Starling College should not be a hindrance to her function as a nonaffiliated IACUC member. Every member should feel free to independently cast their vote in favor or against a motion on the table and abstain as necessary without pressure or undue influence ${ }^{2}$.

It is important to avoid the potential actual or perceived conflicts of interest. Marx could have reassured Rubin by letting her know that there are procedures in place at Starling College with regards to management of conflict of interests and confidentiality (assuming that these are already in place).

Before signing up with Starling College IACUC as a nonaffiliated member, Rubin must also let Great Eastern University (as her employer) know of her plan to ensure that it is alright for her to join an external committee. Most institutions do encourage and allow their staff to participate in external committees as part of their service to the community.

In New Zealand and Australia, members of the Animal Ethics Committee (AEC)-equivalent of the IACUC-must acknowledge in writing (before appointment) their acceptance of the terms of reference of the AEC, including declaration of interests and any requirements for confidentiality required by the institution ${ }^{3}$. In New Zealand, the institution's Code of Ethical Conduct for the Use of Animals in Research, Testing and Teaching (CEC) describes how confidentiality and conflicts of interests will be managed ${ }^{4}$.

Institutions should have clear IACUC/AEC policies and guidelines regarding declaration and management of conflict of interests and confidentiality.
These should also include expectations on all committee members (including nonaffiliated members), highlighting the importance of acting professionally and impartially in carrying out their committee role or professional obligations, to ensure fair and unbiased review of IACUC matters.

\section{Mark Vinson Vallarta ${ }^{\circledR}$, Alyssa Calder and Samantha Cockerill Animal Welfare Office, University of Otago, \\ Dunedin, New Zealand.

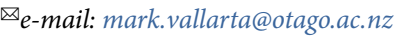

Published online: 24 June 2020

https://doi.org/10.1038/s41684-020-0576-3

References

1. Petrie, W. and Wallace, S., editors. The Care and Feeding of an IACUC: The Organization and Management of an Institutional Animal Care and Use Committee, $2^{\text {nd }}$ Edition. (CRC Press, Florida, 2015).

2. Weichbrod, R., Thompson G. and Norton J., editors. Management of Animal Care and Use Programs in Research, Education, and Testing, $2^{\text {nd }}$ Edition. (CRC Press, Florida, 2018).

3. National Health and Medical Research Council. Australian Code for the Care and Use of Animals for Scientific Purposes, $8^{\text {th }}$ Edition. (National Health and Medical Research Council, Canberra, 2013).

4. National Animal Ethics Advisory Committee. NAEAC Good Practice Guide for the Use of Animals in Research, Testing and Teaching. (New Zealand Ministry for Primary Industries, Wellington, 2019). 